AperTO - Archivio Istituzionale Open Access dell'Università di Torino

Sexually dimorphic phrase organization in the song of the indris (Indri indri)

This is a pre print version of the following article:

Original Citation:

Availability:

This version is available http://hdl.handle.net/2318/1736268

since $2020-12-22 T 10: 56: 43 Z$

Published version:

DOI:10.1002/ajp.23132

Terms of use:

Open Access

Anyone can freely access the full text of works made available as "Open Access". Works made available under a Creative Commons license can be used according to the terms and conditions of said license. Use of all other works requires consent of the right holder (author or publisher) if not exempted from copyright protection by the applicable law. 


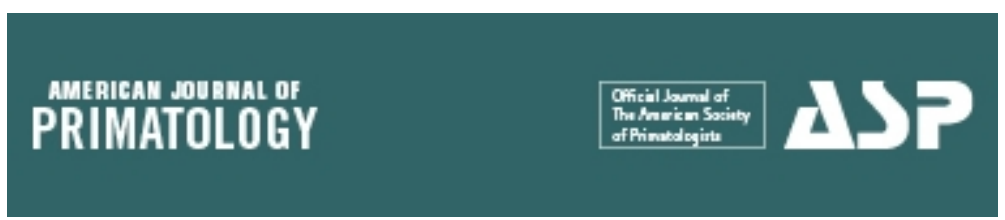

\section{Sexually dimorphic phrase organization in the song of the indris (Indri indri)}

\begin{tabular}{|c|c|}
\hline Journal: & American Journal of Primatology \\
\hline Manuscript ID & AJP-19-0209.R2 \\
\hline Wiley - Manuscript type: & Research Article \\
\hline $\begin{array}{r}\text { Date Submitted by the } \\
\text { Author: }\end{array}$ & 25-Mar-2020 \\
\hline Complete List of Authors: & $\begin{array}{l}\text { Zanoli, Anna; University of Torino, Life Sciences and Systems Biology } \\
\text { De Gregorio, Chiara; University of Torino, Life Sciences and Systems } \\
\text { Biology } \\
\text { Valente, Daria; University of Torino, Life Sciences and Systems Biology } \\
\text { Torti, Valeria; University of Torino, Life Sciences and Systems Biology } \\
\text { Bonadonna, Giovanna; University of Torino, Life Sciences and Systems } \\
\text { Biology } \\
\text { Randrianarison, Rose Marie; GERP (Groupe d'etude et de recherche sur } \\
\text { les primates du Madagascar) } \\
\text { Giacoma, Cristina; University of Torino, Life Sciences and Systems } \\
\text { Biology } \\
\text { Gamba, Marco; University of Torino, Life Sciences and Systems Biology }\end{array}$ \\
\hline $\begin{array}{l}\text { Indicate which taxonomic } \\
\text { group was the subject of your } \\
\text { study (select all that apply or } \\
\text { type another option): }\end{array}$ & Prosimians \\
\hline Keywords: & syntax, language evolution, primates, singing, Levenshtein distance \\
\hline
\end{tabular}

\section{SCHOLARONE $^{\text {TM }}$ \\ Manuscripts}


Sexually dimorphic phrase organization in the song of the indris (Indri indri)

6 Anna Zanoli ${ }^{1}$, Chiara De Gregorio ${ }^{1}$, Daria Valente ${ }^{1}$, Valeria Torti ${ }^{1}$, Giovanna

7 Bonadonna $^{1}$, Rose Marie Randrianarison ${ }^{2,3}$, Cristina Giacoma ${ }^{1} \&$ Marco Gamba $^{1}$

8

$9{ }^{1}$ Department of Life Sciences and Systems Biology, University of Torino, Torino, Italy

$10{ }^{2}$ Groupe d'Étude et de Recherche sur les Primates de Madagascar (GERP),

11 Antananarivo, Madagascar

$12{ }^{3}$ Mention d'Anthropobiologie et de Développement Durable (MADD), Université

13 d'Antananarivo, Antananarivo 101, Madagascar

16 Corresponding Author:

17 Marco Gamba ${ }^{1}$, Department of Life Sciences and Systems Biology, University of

18 Torino, Via Accademia Albertina 13, 10123 Torino, Italy, Tel. +39 0116704560

19 Email address: marco.gamba@unito.it 
35

36

37

38

39

40

\section{Abstract}

Animal acoustic communication often takes the form of complex sequences, composed of multiple distinct acoustic units, which can vary in their degree of stereotypy. Studies of sequence variation may contribute to our understanding of the structural flexibility of primates' songs, which can provide essential ecological and behavioral information about variability at the individual, population, and specific level and provide insights into the mechanisms and drivers responsible for the evolutionary change of communicative traits. We studied intra and inter-individual variation in the song structuring of a singing primate, the indri (Indri indri). Indri groups emit duets and choruses in which they combine long notes, short single units, and phrases consisting of a variable number of units (from two to six) with slightly descending frequency. Males' and females' contributions to the song differ in the temporal and frequency structure of song units and repertoire size. We calculated the similarity of phrase organization across different individual contributions using the Levenshtein distance, a logic distance that expressed the minimum cost to convert a sequence into another and can measure differences between two sequences of data. We then analyzed the degree of similarity within and between individuals and found that: i) the phrase structure of songs varied between reproductive males and females: female structuring of the song showed a higher number of phrases if compared to males; ii) Male contributions to the song were overall more similar to those of other males than were female contributions to the song of other females; iii) male contributions were more stereotyped than female contributions, which showed greater individual flexibility. The picture emerging from phrase combinatorics in the indris is in agreement with previous findings of rhythmic features and song repertoire 
59 size of the indris, which also suggested that female songs are potentially less stereotyped

60 than those of males.

61

62 Keywords: syntax, language evolution, primates, singing, Levenshtein distance

63

64

65 Research Highlights

66 - This study demonstrated that male and female adult indris differed in the phrase organization of their songs.

- Male contributions to the song were overall more similar to those of other males and more stereotyped than females' ones.

\section{Graphical Abstract}

Figure 2 works as graphical abstract for this manuscript. 
79 Communication between conspecifics often involves the use of vocalizations because

80 acoustic signals allow encoding a considerable amount of information in a short time

81 (Bradbury \& Vehrencamp, 2011). Animal vocal signals can be emitted in the form of

82 short vocalizations or given in sequences of variable length (Catchpole \& Slater, 2008).

83 In addition to the well-known example of birdsong, other animals such as insects,

84 amphibians, and mammals (including bats, rodents, primates, and cetaceans) also emit

85 complex acoustic sequences (Kershenbaum et al., 2016). Although animals showed a

86 limited ability to concatenate vocal emissions in phrases when compared to humans

87 (Berwick, Okanoya, Beckers \& Bolhuis, 2011), their vocal sequences may contain

88 information on species and individual identity (e.g., starlings (Sturnus vulgaris), wolves

89 (Canis lupus), dolphins (Tursiops truncatus), and rock hyraxes (Procavia capensis)).

90 Animal vocal sequences may also encode information about external cues such as

91 resource availability, e.g., food calls in chimpanzees (Pan troglodytes), or predator threats

92 in marmots (Marmota spp.; Kershenbaum et al., 2016).

93 The understanding of the role played by the acoustic sequences in a particular species'

94 repertoire often involves the comparison of sequences within and between individuals, as

95 well as within and between groups, so that it is possible to quantify the nature of the

96 variation and potentially correlate it to ecological and behavioral factors (Kershenbaum

97 et al., 2014).

98 So far, the studies of primate call organization focused on contact calls or alarm calls

99 (Clarke, Reichard \& Zuberbühler, 2006) with scarce investigations of song structure

100 variation within contexts (Torti, Gamba, Rabemananjara \& Giacoma, 2013). There is a

101 lack of information about whether primate males and females combine units in songs

102 using different phrase combinations. It is essential to examine the sex-dimorphic traits of 
103 primate songs because knowledge of sex differences in song organization may be critical 104 in our understanding of what is biologically informative, especially in sexually 105 monomorphic species. Moreover, information available on the variability within a species 106 is very little (Honda \& Okanoya, 1999; Takahasi, Yamada \& Okanoya, 2010). Few 107 investigations on primate vocal sequences are currently available and none of them are 108 evaluating the stereotypy of song structure between sexes using a string metric (Gustison, 109 Semple, Ferrer-i-Cancho \& Bergman, 2016). While traditional methods may not apply to 110 a wide array of questions, string metrics can be used to investigate different organizational 111 levels, are entirely objective, and their results are verifiable (Heeringa, 2004).

112 Indris (Indri indri, Gmelin, 1788) represent a distinctive species for studying vocal 113 communication because of their rich repertoire (Maretti, Sorrentino, Finomana, Gamba 114 \& Giacoma, 2010; Valente et al., 2019) and the impressive loud songs, unique among 115 lemurs (Gamba et al., 2016; Torti et al., 2017), which can be heard at a distance up to 2 $116 \mathrm{~km}$ (Pollock, 1986). Data on sound pressure levels revealed that the sound levels of the 117 indri's song reached $110 \mathrm{~dB}$ (estimated at $0.50 \mathrm{~m}$; Torti, pers. obs.). This level can be 118 compared to ring-tailed lemurs (Lemur catta), which showed a call amplitude ranging 119 between 85 and $89 \mathrm{~dB}$ (at $1 \mathrm{~m}$, Macedonia, 1993). The song of the indris, which lasts 40$120250 \mathrm{~s}$, consists of a long series of modulated units, organized in phrases (Gamba, Favaro,

121 Torti, Sorrentino \& Giacoma, 2011), uttered simultaneously by males and females, 122 including juveniles, of the same group (Maretti et al., 2010). These types of units are 123 emitted exclusively during the song (Valente et al., 2019).

124 Previous research showed that the indris can emit songs in different contexts and that the 125 song can elicit different behaviors depending on its acoustic structure. Songs given in 126 different contexts showed differences in their temporal structure that are distinguishable 
127 by visual inspection of the spectrograms and by ear (Torti et al. 2013). Cohesion songs

128 were emitted when the individuals of a group were dispersed in their territory, while

129 advertisement songs were usually given when the animals of the same group were in

130 visual contact at the boundary of their territory (Torti et al., 2013). Cohesion songs were

131 followed by emitters traveling significantly further than following the advertisement

132 song, confirming the different functions of the song uttered in different contexts (i.e.,

133 cohesion songs bring together the members of a group, and advertisement songs inform

134 neighbors about the sex, age, and status of singing individuals). Other studies have shown

135 that male and female contributions to the song differ, both quantitatively and

136 qualitatively, in the temporal structure of the units emitted (Giacoma, Sorrentino,

137 Rabarivola \& Gamba, 2010; Sorrentino, Gamba \& Giacoma, 2012). Vocal sexual

138 dimorphism is also present in the modulation of the frequency of vocal utterances, in the

139 duration of unit types and the rhythmic structure of a contribution (Gamba et al., 2016;

140 De Gregorio et al., 2018).

141 Since the indris' songs can be interpreted as a string of easily identifiable phrases (Gamba

142 et al., 2016), they represent an ideal case for the study of the variability of phrase

143 concatenation in primate songs. Among the methods for investigating different levels of

144 structural variation in acoustic displays, we chose the Levenshtein distance, which is a

145 quantitative method for measuring the similarity of sequences (hereafter LD; Margoliash,

146 Staicer \& Inoue, 1991). The LD is a logical distance commonly used to quantify the

147 difference between two strings of data (e.g., human words, sequences of visual

148 movements or sequences of song themes; Gooskens \& Heeringa, 2004). This technique

149 has often been used to measure similarity in human dialects (Wieling, Montemagni,

150 Nerbonne \& Baayen, 2014), and it has been applied to animal vocal sequences, but for a 
151 very limited number of species (Indigo bunting, Passerina cyanea, Margoliash et al., 152 1991; Willow warbler, Phylloscopus trochilus, Gil \& Slater, 2000; Humpback whale, 153 Megaptera novaeangliae: Helweg, Cato, Jenkins, Garrigue \& McCauley, 1998; Tougaard 154 \& Eriksen, 2006; Garland et al., 2012).

155 Although songs are often referred to as a male's prerogative, we have particular insights 156 showing that monogamous females may also use the song overlapping male song 157 functions (e.g., Eastern whip bird (Psophodes olivaceus), Rogers, Langmore, \& Mulder, 158 2007; Levin, 1996a; 1996b). Females may use songs for mate attraction (Rogers et al., 159 2007), and they may even show a more elaborated song repertoire (Australian magpies 160 (Gymnorhina tibice Brown \& Farabaugh, 1991). Like Eastern whip birds and Australian 161 magpies, indris are monogamous (Torti et al., 2017; Bonadonna et al., 2019), form groups 162 that occupy non-overlapping areas in the forest (Bonadonna et al., 2017), and use the 163 songs to inform neighboring groups about the occupation of a territory and to actively 164 defend resources during group encounters (Torti et al., 2013). Thus, we hypothesized that 165 the female contribution to the song would be structurally different from that of males.

166 Studies of song structure in bird duets also suggested that females' songs would be more 167 acoustically variable than that of males (Logue \& Gammon, 2004), in line with the 168 territorial model of bird duet evolution (Farabaugh, 1982). In birds, duetting occurs most 169 commonly where birds hold year-round territories, and it is associated with sexually 170 monomorphic species that form long-term monogamous pair bonds (Riebel, Odom, 171 Langmore \& Hall, 2019). Indri females showed significantly higher variation in the 172 rhythm of their contributions to the song and a higher potential to synchronize with males 173 (De Gregorio et al., 2018). Thus, we hypothesized that the adjustment in the rhythmic 174 structure of their contribution would also be reflected in a sexually dimorphic phrases 
175 combination, where one should expect males to produce songs with a more stereotyped

176 structure. Similarly to pair living bird species (Rogers et al., 2007), indri females may use

177 songs for mate guarding and attraction, and song structural variability and complexity

178 may have evolved to provide conspecifics with information on females' fitness and 179 survival.

\section{Methods}

\section{Observations and recordings}

185 We studied 8 groups $\left(\mathrm{N}=36\right.$ individuals) living in the Maromizaha Forest $\left(18^{\circ} 56^{\prime} 49^{\prime \prime} \mathrm{S}\right.$, $\left.18648^{\circ} 27^{\prime} 53 " \mathrm{H}\right)$. We recorded the animals between 2011 and 2017. We observed one social 187 group per week, from Monday to Friday approximately from 6 AM to 1 PM, when the 188 animals usually start resting and sleeping until the day after (Pollock, 1975). All 189 recordings were carried out without the use of playback stimuli, and nothing was done to 190 modify the behavior of the indris. We recorded 142 songs, consisting of duets and

191 choruses with a maximum of five individuals singing in the same song. For the analysis,

192 we only considered the contribution of the reproductive individuals, for a total of 17 focal 193 animals from eight social groups: nine reproductive adult males, and eight reproductive 194 adult females. An example of an indri song and the singers' contributions is shown in

195 Figure 1. The different number of males and females is motivated by the fact that, during 196 the study period, the reproductive male of a group changed. All the songs were recorded 197 using solid-state recorders (Olympus LS05, Tascam DR-100, Tascam DR-05) with a 198 sampling rate of $44.1 \mathrm{kHz}$ (16-bit depth) during all the recording sessions. When 
199 recording the songs, we were always at a distance between 2 and $20 \mathrm{~m}$ from the animals,

200 with the microphone oriented toward the focal singing individuals. We always kept visual

201 contact with the vocalizing animals and maximized our efforts to face the focal animals

202 during the emission of the song. Since indri songs emitted in different contexts have

203 different acoustic structure, in order to avoid any bias due to these differences, we

204 considered, from multiple years, only those songs that were labeled as advertisement

205 songs and were recorded in the same context (Torti et al., 2013). Using the focal animal

206 sampling technique (Altmann, 1974), we were able to attribute each vocalization to its

207 signaler. We will refer to every individual uttered portion within a song or a chorus as an

208 'individual contribution'.

209 During this study, we did not have any physical contact with the animals, and we recorded

210 only spontaneously emitted songs. We have received permits for this research, each year,

211 from "Direction des Eaux et Forêts" and "Madagascar National Parks": 2011 - N

212 274/11/MEF/SG/D GF/DCB.SAP/SCB, 2012 N²45/12/MEF/SG/DGF/DCB.SAP/SCB,

2132014 - N066/14/MEF/SG/DGF/DCB.SAP/SCB, 2015 - N 180/ 15/ MEEMF/ SG/ DGF/

214 DAPT/ SCBT; 2016 - N 98/ 16/ MEEMF/ SG/ DGF/ DAPT/ SCB.Re and N² 217/

215 16/MEEMF/ SG/ DGF/ DSAP/ SCB.Re, 2017 - 73/17/MEEF/SG/DGF/DSAP/SCB.RE.

216 The data collection in 2013 did not require a permit because performed by our Malagasy

217 collaborators only.

218 We adhered to applicable international, national, and/or institutional guidelines for the

219 study on animals and nonhuman primates, including the American Society of

220 Primatologist (ASP) Principle for the Ethical Treatment of nonhuman Primates, and the 
221 European Union directive guidelines for the study on animals and nonhuman primates 222 (Directive 2010/63/EU). The study did not require IACUC approval.

\section{Acoustic and statistical analyses}

224 We edited segments containing indri songs using Praat 6.0.30 (Boersma \& Weenink 225 2008) and BORIS 5.1 (Friard \& Gamba 2016). For each recorded song, we created a 226 spectrogram with a view range between 0 and $5000 \mathrm{~Hz}$, a window length of $0.09 \mathrm{~s}$, and a 227 dynamic range of $65.0 \mathrm{~dB}$. We saved each song in a single audio file in WAV format 228 (Waveform audio file format). We saved the information related to the identity of each 229 singer in a Praat textgrid. We then labeled all the vocal units (each single sound 230 constituting the modulated part of the song; Thalmann, Geissmann, Simona \& Mutschler, 231 1993) according to their belonging to a song portion (long notes or descending phrases, 232 see Torti et al., 2013 for details) and to a descending phrase (hereafter, DP; see Torti et 233 al., 2017 for details). Songs given in different contexts showed differences in their 234 temporal structure that are distinguishable by visual inspection of the spectrograms and 235 by ear (Torti et al. 2013). We considered phrases consisting of two (DP2), three (DP3), 236 four (DP4), five (DP5), and six (DP6) units. This information was saved in Praat and 237 exported to a Microsoft $($ Excel spreadsheet (Gamba, Friard \& Giacoma, 2012). Since all 238 the steps of the labeling process have been done by a single operator (A.Z.), we avoided 239 the possibility of encountering errors due to observer differences. To understand whether 240 there were differences in song structure between sexes, we investigated the DPs similarity 241 in each contribution. We transformed each contribution in a string of labels separated by 242 a break symbol (e.g., DP2|DP3|DP4|DP3). The resulting string represents the 243 concatenation of the phrases uttered within a contribution (and it is a measure of phrase 
244 organization). From the 142 songs, we obtained 142 strings for females (with an average 245 of 17.88 songs per individual, $\mathrm{SD}=5.44$ ), and 119 strings for males (with an average of 24613.22 songs per individual, $\mathrm{SD}=5.91)$. Using $\mathrm{R}(\mathrm{R}$ Core Team, 2015; version 3.3.3), we 247 calculated the Levenshtein distance (LD) for each pair of strings 248 (package stringdist 0.9.4.2 in R; van der Loo, 2014) because this methodology provides 249 a robust quantitative approach for the study of animal acoustic sequences (Kershenbaum $250 \&$ Garland, 2015). The distance calculates the minimum number of necessary changes 251 (insertions, deletions, and substitutions) to transform one string into another (Kohonen, 252 1985). We obtained a squared matrix consisting of the distances between each pair of strings, then averaged LDs and calculated within- and between-individual means (Fig. 2), to investigate whether females and males differed in their degree of variation. For this purpose, we ran Mantel tests (9999 randomizations) using a matrix featuring the average 256 individual means against a model matrix consisting of 0 when the corresponding 257 individuals were of the same sex (Krull et al., 2012), and 1 when they were opposite sexes 258 (package vegan in R; Oksanen et al., 2013). When investigating differences at the group 259 level or within-sex, we used the non-parametric paired samples Wilcoxon test to compare 260 the average individual LDs of each member of a pair or the within- versus between261 individual LDs because, with such a small sample size, the Mantel test is not 262 recommended (Legendre \& Fortin, 1989). Only for the Wilcoxon test, the group in which 263 the male changed was entered twice, considering the two pairs as different groups. We 264 obtained a lower number of male contributions because the reproductive females also 265 engaged in duets with immature male offspring $(\mathrm{N}=23)$. 


\section{Results}

268 We analyzed 261 individual contributions consisting of a total of 2018 phrases. We 269 obtained $77 \pm 21$ (mean \pm standard deviation) phrases per male and $78 \pm 23$ phrases per 270 female. We found that average phrase duration was $1.285 \mathrm{~s}$ (range: $0.380-3.000 \mathrm{~s}$ ). The 271 number of phrases in the individual song ranged between 2 and 27.

272 We found a significant difference between the LDs calculated for males and females, 273 where females showed higher average individual means than males (Mantel test: $\mathrm{r}=$ $2740.167, \mathrm{P}=0.002$; Fig. 2). In all groups, the females had higher $\mathrm{LDs}(\mathrm{LD}=6.497+1.674)$ 275 than males $(\mathrm{LD}=3.946+0.814)$, showing that female contribution to the song was less 276 stereotyped (Fig. 3, Wilcoxon paired test: $\mathrm{V}=0, \mathrm{df}=7 ; \mathrm{P}=0.008$ ). It is noticeable that 277 the individuals Eva, which sang with three different males and had a high number of 278 recordings $(\mathrm{N}=39)$, showed remarkable differences compared to other females. Both 279 females and males showed a higher variability at between-individuals $\left(\mathrm{LD}_{\text {females }}=7.386\right.$ $\left.280+0.709, \mathrm{LD}_{\text {males }}=4.885+0.325\right)$ than within-individual level (Fig. 3), except for the 281 females of groups 4 and 8 . Overall, we found a significant difference between within- and 282 between-individual LDs (Wilcoxon paired test: $\mathrm{V}=0, \mathrm{df}=7 ; \mathrm{P}=0.008$ ).

\section{Discussion}

284 We examined differences in the order of phrases emitted during the songs by reproductive

285 male and female indris living in the same population. We hypothesized that female 286 contributions to the song may function differently in phrase concatenation from those of 287 males. We found support for our predictions. The phrase structure of songs indeed 288 differed between males and females, and female contributions were less stereotyped than 
289 those of males. The LDs showed that the between-individual stereotypy of male 290 contributions was higher than females' one. Males, therefore, appeared to produce songs 291 that are overall more similar to those of other males. In agreement with previous studies 292 that reported sexual dimorphism in the overall timing and repertoire size (Giacoma et al., 293 2010), and in the frequency modulation, duration and rhythm (Gamba et al., 2016; Torti 294 et al., 2017, De Gregorio et al., 2018), we found that male and female indris also differed 295 in the phrase organization of their songs. Female structuring of the song showed a higher 296 number of phrases if compared to males, independently of the phrases being of the same 297 or different type. This result is in line with previous studies on family-living and pair298 bonded primate and bird species (Deputte, 1982; Savage, Snowdon, Giraldo \& Soto, 299 1996; Snowdon, 2017; Riebel et al., 2019; Levin, 1996a; 1996b), endorsing that in a 300 socially monogamous, monomorphic species which holds year-round territories, sex 301 differences in vocal output are frequent (Marshall \& Marshall, 1976). Furthermore, 302 despite the fact that songs are considered to be males' peculiar features (Cowlishaw, 303 1996), our results confirm that also monogamous females use songs and that female song 304 can be more elaborate than those of males. Female song phrase concatenation is more 305 complex than males' because even if males are playing the primary role in territorial 306 defense, females' role in territorial disputes can be essential. Female songs may be critical 307 for advertising their identity as well as resources holding potential. For instance, vocal 308 fights, in which females and males are singing together, are often sufficient to resolve 309 group encounters, reducing the occurrence of physical fights (Bonadonna et al., 2020).

310 Future studies may investigate whether female dispersal distance and territorial changes

311 over the years may contribute to a deeper understanding of this sex-dimorphic variation.

312 Expanding previous findings that showed how indri female contribution to the song was 
313 more varied in the rhythm (De Gregorio et al., 2018), we showed that the combination

314 and repertoire of the phrases are also more extensive than those shown by males. Females

315 not only have a broader repertoire of units, but they also emit descending phrases that we

316 did not observe in males (e.g., descending phrases of six units). Considering those

317 previous findings, our results may suggest that the differences in song structuring could

318 be used to convey information about the sex and the status of the singers that can be

319 assessed at a distance by conspecifics.

320 In agreement with previous findings on the different role of males and females during the

321 song (Giacoma et al., 2010), we found that female song is potentially more distinctive

322 than the male one. These results are in agreement with previous findings on birds (Brown

$323 \&$ Farabaugh, 1991), confirming that in those species in which females are involved in

324 territorial defense, their repertoires are as large or larger than those of males, on the level

325 of both units and phrases. Territorial defense is crucial for survival and reproduction in

326 pair-bonding species that occupy stable territories, and even if female involvement in

327 territorial defense is different from that of the reproductive male, they participate in

328 joining with their partner. An increasing body of literature (e.g., Hall, Rittenbach, \&

329 Vehrencamp, 2015) supported the view that same-sex competition is the primary driver

330 of female song elaboration. It can be the case of the indris, where females may benefit

331 from multiple mating partners to increase tolerance by neighboring males (Bonadonna et

332 al., 2014). As mentioned above, females can advertise the occupancy of an area as well

333 as their quality and resource-holding potential. In support of the higher variability in

334 female song structure, there is also the recent evidence that genetic relatedness may play

335 a critical role in determining the characteristics of DPs in males, whereas it may have a

336 lesser impact on female songs (Torti et al., 2017). A more variable song structure may 
337 add up to a more flexible structuring of the phrase notes, but further investigations are 338 needed.

339 This work also expands on and complements previous studies on humpback whales 340 (Helweg et al., 1998; Tougaard \& Eriksen, 2006; Garland et al., 2012), showing that the

341 Levenshtein distance is simple, efficiently computable and highly applicable to any 342 behavioral data that are produced in a sequence. Our results confirmed that the 343 Levenshtein distance method is a simple but powerful technique that can be applied to 344 assess stereotypy or divergence between sexes.

\section{Acknowledgements}

347 We thank two anonymous Reviewers and the Editor for their careful reading of our 348 manuscript and their many insightful comments and suggestions. This research was 349 supported by Università degli Studi di Torino and by grants from the Parco Natura Viva350 Centro Tutela Specie Minacciate. We are grateful to GERP and Dr Jonah Ratsimbazafy.

351 We thank Dr, Cesare Avesani Zaborra and Dr Caterina Spiezio for helping us with the 352 organization of the field station in Maromizaha. We are grateful to the researchers and 353 the international guides, for their help and logistical support. We also thank San Diego 354 Zoo Global, LDVI, Dr Chia L. Tan. 


\section{References}

359 Altmann, J. (1974). Observational study of behavior: sampling methods. Behaviour, 49, 360 227-267. DOI: $10.1163 / 156853974 X 00534$

361 Berwick, R. C., Okanoya, K., Beckers, G. J. L., \& Bolhuis, J. J. (2011). Songs to

362 syntax: the linguistics of birdsong. Trends in Cognitive Sciences, 15, 113-121. DOI:

363 10.1016/j.tics.2011.01.002

364 Boersma, P., \& Weenink, D. (2005). Praat: doing phonetics by computer [Computer 365 program].

366 Bonadonna, G., Torti, V., Sorrentino, V., Randrianarison, R. M., Zaccagno, M., Gamba, 367 M., \& Giacoma, C. (2017). Territory exclusivity and intergroup encounters in the indris 368 (Mammalia: Primates: Indridae: Indri indri) upon methodological tuning. The European 369 Zoological Journal, 84, 238-251. DOI: 10.1080/24750263.2017.1318184

370 Bonadonna, G., Torti, V., De Gregorio, C., Valente, D., Randrianarison, R. M., Pozzi,

371 L., M., Gamba, M., \& Giacoma, C. (2019). Evidence of genetic monogamy in the lemur 372 Indri (Indri indri). American Journal of Primatology, 81(6), e22993. DOI:

373 10.1002/ajp.22993

374 Bonadonna, G., Zaccagno, M., Torti, V., Valente, D., De Gregorio, C., Randrianarison, 375 R. M., ... \& Giacoma, C. (2020). Intra-and Intergroup Spatial Dynamics of a Pair-Living 376 Singing Primate, Indri indri: A Multiannual Study of Three Indri Groups in 377 Maromizaha Forest, Madagascar. International Journal of Primatology, 1-22. DOI: 378 10.1007/s10764-019-00127-5 
379 Bradbury, J.W., \& Vehrencamp, S.L. (2011). Principles of animal communication.

380 Sinauer, Sunderland.

381 Brown, E. D., \& Farabaugh, S. M. (1991). Song sharing in a group-living songbird, the

382 Australian magpie, Gymnorhina tibicen. Part III. Sex specificity and individual

383 specificity of vocal parts in communal chorus and duet songs. Behaviour, 118, 244-274.

384 Catchpole, C. K., \& Slater, P. J. R. (2008). Bird song: biological themes and variations.

385 Cambridge University Press, Cambridge.

386 Clarke, E., Reichard, U. H., \& Zuberbühler, K. (2006). The syntax and meaning of wild

387 gibbon songs. PloS one, 1(1), e73. DOI: 10.1371/journal.pone.0000073

388 Cowlishaw, G. U. Y. (1996). Sexual selection and information content in gibbon song

389 bouts. Ethology, 102(2), 272-284. DOI: 10.1111/j.1439-0310.1996.tb01125.x

390 De Gregorio, C., Zanoli, A., Valente, D., Torti, V., Bonadonna, G., Randrianarison, R.

391 M., Giacoma, C., \& Gamba, M. (2019). Female indris determine the rhythmic structure

392 of the song and sustain a higher cost when the chorus size increases. Current Zoology,

393 65, 89-97. DOI: 10.1093/cz/zoy058

394 Deputte, B. L. (1982). Duetting in male and female songs of the white-cheeked gibbon

395 (Hylobates concolor leucogenys). In C. T. Snowdon, C. H. Brown, \& M. R. Petersen

396 (Eds.), Primate communication (pp. 67-93). New York: Cambridge University Press.

397 Farabaugh, S. M. (1982). The ecological and social significance of duetting. In: D. E.

398 Kroodsma \& E. H. Miller (Eds.), Acoustic Communication in Birds Vol. 2. (pp. 85-124).

399 New York, USA: Academic Press. 
400 Friard, O., \& Gamba, M. (2016). BORIS: a free, versatile open-source event-logging

401 software for video/audio coding and live observations. Methods in Ecology and

402 Evolution, 7, 1325-1330. DOI:10.1111/2041-210X.12584

403 Gamba, M., Favaro, L., Torti, V., Sorrentino, V., \& Giacoma, C. (2011). Vocal tract

404 Flexibility and variation in the vocal output in wild indris. Bioacoustics, 20, 251-265.

405 DOI: $10.1080 / 09524622.2011 .9753649$

406 Gamba, M., Friard, O., \& Giacoma, C. (2012). Vocal tract morphology determines

407 species-specific features in vocal signals of lemurs (Eulemur). International Journal of

408 Primatology, 33(6), 1453-1466. DOI:10.1007/s10764-012-9635-y

409 Gamba, M., Torti, V., Estienne, V., Randrianarison, R. M., Valente, D., Rovara, P., \&

410 Giacoma, C. (2016). The indris have got rhythm! Timing and pitch variation of a

411 primate song examined between sexes and age classes. Frontiers in neuroscience, 10,

412 249. DOI: $10.3389 /$ fnins.2016.00249

413 Garland, E. C., Lilley, M. S., Goldizen, A. W., Rekdahl, M. L., Garrigue, C., \& Noad,

414 M. J. (2012). Improved versions of the Levenshtein distance method for comparing

415 sequence information in animals' vocalisations: tests using humpback whale song.

416 Behaviour, 149, 1413-1441. DOI: 10.1163/1568539X-00003032

417 Giacoma, C., Sorrentino, V., Rabarivola, C., \& Gamba, M. (2010). Sex differences in

418 the song of Indri indri. International Journal of Primatology, 31, 539-551. DOI:

$419 \quad 10.1007 / \mathrm{s} 10764-010-9412-8$ 
420 Gil, D., \& Slater, P. J. (2000). Song organisation and singing patterns of the willow

421 warbler, Phylloscopus trochilus. Behaviour, 137(6), 759-782.

422 Gooskens, C. \& Heeringa, W. (2004). Perceptive evaluation of Levenshtein dialect

423 distance measurements using Norwegian dialect data. Language variation and change, 424 16, 189-207. DOI: 10.1017/S0954394504163023

425 Gmelin, J. F. (1788). Systema naturce: per Regna tria naturae, secundum classes, 426 ordines, genera, species, cum characteribus, differentiis, synonomis, locis (Vol. 1, No.

427 6). Beer.

428 Gustison, M. L., Semple, S., Ferrer-i-Cancho, R., \& Bergman, T. J. (2016). Gelada

429 vocal sequences follow Menzerath's linguistic law. Proceedings of the National 430 Academy of Sciences, 113, E2750-E2758. DOI: 10.1073/pnas.1522072113

431 Hall, M. L., Rittenbach, M. R., \& Vehrencamp, S. L. (2015). Female song and vocal 432 interactions with males in a neotropical wren. Frontiers in Ecology and Evolution, 3, 433 12. DOI: $10.3389 /$ fevo.2015.00012

434 Heeringa, W. J. (2004). Measuring dialect pronunciation differences using Levenshtein 435 distance (Doctoral dissertation, University Library Groningen).

436 Helweg, D. A., Cato, D. H., Jenkins, P. F., Garrigue, C., \& McCauley, R. D. (1998).

437 Geographic variation in South Pacific humpback whale songs. Behaviour, 135, 1-27. 438 DOI: $10.1163 / 156853998793066438$

439 Honda, E. \& Okanoya, K. (1999). Acoustical and syntactical comparisons between 440 songs of the white-backed Munia (Lonchura striata) and its domesticated strain, the 
441 Bengalese finch (Lonchura striata var. domestica). Zoological Science, 16, 319-326.

442 DOI: $10.2108 /$ zsj. 16.319

443 Kershenbaum, A., Blumstein, D. T., Roch, M. A., Akçay, Ç., Backus, G., Bee, M. A., ...

$444 \&$ Coen, M. (2016). Acoustic sequences in non-human animals: a tutorial review and 445 prospectus. Biological Reviews, 91(1), 13-52. DOI: $10.1111 /$ brv.12160

446 Kershenbaum, A. \& Garland, E. C. (2015). Quantifying similarity in animal vocal 447 sequences: which metric performs best? Methods in Ecology and Evolution, 6, 1452448 1461. DOI: $10.1111 / 2041-210 X .12433$

449 Kershenbaum, A., Bowles, A. E., Freeberg, T. M., Jin, D. Z., Lameira, A. R., \& Bohn, 450 K. (2014). Animal vocal sequences: not the Markov chains we thought they

451 were. Proceedings of the Royal Society B: Biological Sciences, 281(1792), 20141370.

452 DOI: $10.1098 \% 2 F r s p b .2014 .1370$

453 Kohonen, T. (1985). Median strings. Pattern Recognition Letters, 3, 309-313. DOI: $454 \quad 10.1016 / 0167-8655(85) 90061-3$

455 Krull, C. R., Ranjard, L., Landers, T. J., Ismar, S. M., Matthews, J. L., \& Hauber, M. E. 456 (2012). Analyses of sex and individual differences in vocalizations of Australasian 457 gannets using a dynamic time warping algorithm. The Journal of the Acoustical Society 458 of America, 32, 1189- 98. DOI: 10.1121/1.4734237

459 Legendre, P., \& Fortin, M. J. (1989). Spatial pattern and ecological 460 analysis. Vegetatio, 80(2), 107-138. 
461 Levin, R. N. (1996a). Song behaviour and reproductive strategies in a duetting wren, 462 Thryothorus nigricapillus: I. Removal experiments. Animal Behaviour, 52, 1093-1106. 463 DOI: 10.1006/anbe.1996.0257

464 Levin, R. N. (1996b). Song behaviour and reproductive strategies in a duetting wren, 465 Thryothorus nigricapillus: II Playback experiments. Animal Behaviour, 52, 1107-1117. 466 DOI: 10.1006/anbe.1996.0258

467 Logue, D. M., \& Gammon, D. E. (2004). Duet song and sex roles during territory 468 defence in a tropical bird, the black-bellied wren, Thryothorus fasciatoventris. Animal 469 Behaviour, 68(4), 721-731. DOI: 10.1016/j.anbehav.2003.10.026

470 Macedonia, J. M. (1993). The vocal repertoire of the ring-tailed lemur (Lemur 471 catta). Folia primatologica, 61(4), 186-217.

472 Maretti, G., Sorrentino, V., Finomana, A., Gamba, M., \& Giacoma, C. (2010). Not just 473 a pretty song: an overview of the vocal repertoire of Indri indri. Journal of 474 Anthropological Sciences, 88, 151-165.

475 Margoliash, D., Staicer, C. A., \& Inoue, S. A. (1991). Stereotyped and plastic song in 476 adult indigo buntings, Passerina cyanea. Animal Behaviour, 42, 367-388. DOI:

$477 \quad 10.1016 / \mathrm{S} 0003-3472(05) 80036-3$

478 Marshall, J. T., \& Marshall, E. R. (1976). Gibbons and their territorial songs. Science, $479193,235-237$. 
480 Oksanen, J., Blanchet, F. G., Kindt, R., Legendre, P., Minchin, P. R., O’hara, R. B., ...

481 \& Oksanen, M. J. (2013). Package 'vegan'. Community ecology package, version, 2(9), $482 \quad 1-295$.

483 Pollock, J. I. (1975). The social behaviour and ecology of Indri indri (Doctoral 484 dissertation, University of London).

485 Pollock, J. I. (1986). The song of the Indris (Indri indri; Primates: Lemuroidea): natural 486 history, form and function. International Journal of Primatology, 7, 225-267. DOI:

$487 \quad 10.1007 / \mathrm{BF} 02736391$

488 R Core Team (2015). R: A Language and Environment for Statistical Computing.

489 Vienna: R Foundation for Statistical Computing. Available online at: http://www.R-

490 project.org/

491 Riebel, K., Odom, K. J., Langmore, N. E., \& Hall, M. L. (2019). New insights from

492 female bird song: towards an integrated approach to studying male and female

493 communication roles. Biology letters, 15(4), 20190059. DOI: 10.1098/rsbl.2019.0059

494 Rogers, A. C., Langmore, N. E., \& Mulder, R. A. (2007). Function of pair duets in the 495 eastern whipbird: cooperative defense or sexual conflict?. Behavioral Ecology, 18(1), 496 182-188. DOI:10.1093/beheco/ar1070

497 Savage, A., Snowdon, C. T., Giraldo, H., \& Soto, H. (1996). Parental care patterns and 498 vigilance in wild cotton-top tamarins (Saguinus oedipus). In M. Norconk, A.

499 Rosenberger, \& P. A. Garber (Eds.), Adaptive radiations of neotropical primates (pp. 500 187-199). New York: Plenum Press. 
501 Snowdon, C. T. (2017). Vocal communication in family-living and pair-bonded

502 primates. In Primate Hearing and Communication (pp. 141-174). Springer, Cham.

503 Sorrentino, V., Gamba, M., \& Giacoma, C. (2012). A quantitative description of the

504 vocal types emitted in the indri's song. Leaping ahead: advances in prosimian biology,

505 315-322. DOI: 10.1007/978-1-4614-4511-1_35

506 Takahasi, M., Yamada, H., \& Okanoya, K. (2010). Statistical and Prosodic Cues for

507 Song Segmentation Learning by Bengalese Finches (Lonchura striata var. domestica).

508 Ethology, 116, 481-489. DOI: 10.1111/j.1439-0310.2010.01772.x

509 Thalmann, U., Geissmann, T., Simona, A., \& Mutschler, T. (1993). The indris of

510 Anjanaharibe-Sud, northeastern Madagascar. International Journal of

511 Primatology, 14(3), 357-381.

512 Torti, V., Gamba, M., Rabemananjara, Z. H., \& Giacoma, C. (2013). The songs of the

513 indris (Mammalia: Primates: Indridae): contextual variation in the long-distance calls of

514 a lemur. Italian Journal of Zoology, 80, 596-607. DOI: 10.1080/11250003.2013.845261

515 Torti, V., Bonadonna, G., De Gregorio, C., Valente, D., Randrianarison, R. M., Friard,

516 O., ... Giacoma, C. (2017). An intra-population analysis of the indris' song dissimilarity

517 in the light of genetic distance. Scientific reports, 7, 10140. DOI: 10.1038/s41598-017-

$518 \quad 10656-9$

519 Tougaard, J., \& Eriksen, N. (2006) Analysing differences among animal songs

520 quantitatively by means of the Levenshtein distance measure. Behaviour, 143, 239-252.

$521 \quad$ DOI: $10.1163 / 156853906775900685$ 
522 Valente, D., De Gregorio, C., Torti, V., Miaretsoa, L., Friard, O., ...Gamba M. (2019).

523 Finding Meanings in low dimensional structures: Stochastic Neighbor Embedding

524 applied to the analysis of Indri indri vocal repertoire. Animals, 9, 5, 243. DOI:

$525 \quad 10.3390 /$ ani 9050243

526 van der Loo, M. (2014). The stringdist package for approximate string matching. The $R$

527 Journal, 6, 111-122. https://CRAN.R-project.org/package=stringdist

528 Wei, T., \& Simko, V. (2017). R package "corrplot": Visualization of a Correlation

529 Matrix. https://github.com/taiyun/corrplot

530 Wieling, M., Montemagni, S., Nerbonne, J., \& Baayen, R. H. (2014). Lexical

531 differences between Tuscan dialects and standard Italian: Accounting for geographic

532 and sociodemographic variation using generalized additive mixed modeling. Language,

533 90, 669-692. DOI: 10.1353/lan.2014.0064

534

535

536

537

538

539

540 
541 Figure legend:

542 Figure 1: Spectrographic and schematic representation of an indri song. Spectrograms

543 of an indri song (a) showing a typical sequence of units given by one male and one

544 female. Schematic representation of the fundamental frequency of the descending

545 phrase units given by one male (b) and one female (c). Box fill patterns denote the

546 phrase type: black boxes mark single units (SU), horizontal lines boxes mark DP2,

547 diagonal lines boxes mark DP3, wavy lines boxes mark DP4, and checkered boxes mark

548 DP5. The spectrograms were generated in Praat with the following parameters: window

549 length: $0.05 \mathrm{~s}$; dynamic range: $50 \mathrm{~dB}$; frequency range: 0 to $10.000 \mathrm{~Hz}$ (a), 0 to 3.000

$550 \mathrm{~Hz}(\mathrm{~b}, \mathrm{c})$.

$551 \quad$ Figure 2: The Levenshtein Distances showing song structuring in male and female

552 indris of the studied groups. Individuals are shown on the vertical axis; sexes are shown

553 on the horizontal axis. Dot size and color refer to the Levenshtein Distance: the darker

554 and bigger the dots, the higher are the distances between the individual contributions to

555 the song. This plot was generated using the R package corrplot (vers. 0.84; Wei \&

556 Simko, 2017).

557 Figure 3: The average Levenshtein Distance among sexes and individuals, in the eight

558 studied groups. Bar plot describing the individual and overall degree of stereotypy and

559 variability expressed by the average Levenshtein Distances (LDs). Within-individual

560 LDs are reported for females (white bars) and males (black bars), as well as between-

561 individual LDs (grey bars for females, striped bars for males). Group 3 is reported twice

562 because the male of the reproductive pairs changed in 2014. Capped lines represent

563 Standard Deviation. 


\section{Research Highlights}

- This study demonstrated that male and female adult indris differed in the phrase organization of their songs.

- Male contributions to the song were overall more similar to those of other males and more stereotyped than females' ones. 

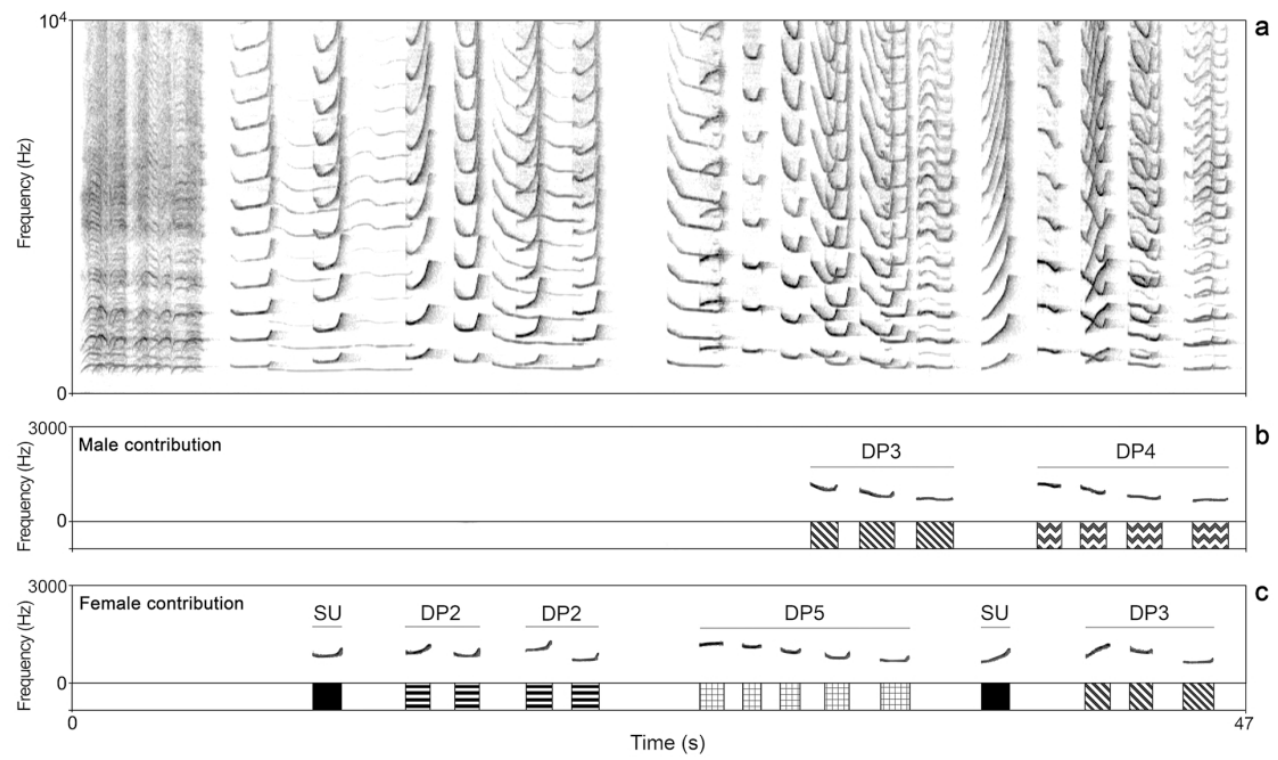

Figure 1: Spectrographic and schematic representation of an indri song. Spectrograms of an indri song (a) showing a typical sequence of units given by one male and one female. Schematic representation of the fundamental frequency of the descending phrase units given by one male (b) and one female (c). Box fill patterns denote the phrase type: black boxes mark single units (SU), horizontal lines boxes mark DP2, diagonal lines boxes mark DP3, wavy lines boxes mark DP4, and checkered boxes mark DP5. The spectrograms were generated in Praat with the following parameters: window length: $0.05 \mathrm{~s}$; dynamic range: $50 \mathrm{~dB}$; frequency range: 0 to $10.000 \mathrm{~Hz}(a), 0$ to $3.000 \mathrm{~Hz}(b, c)$. 


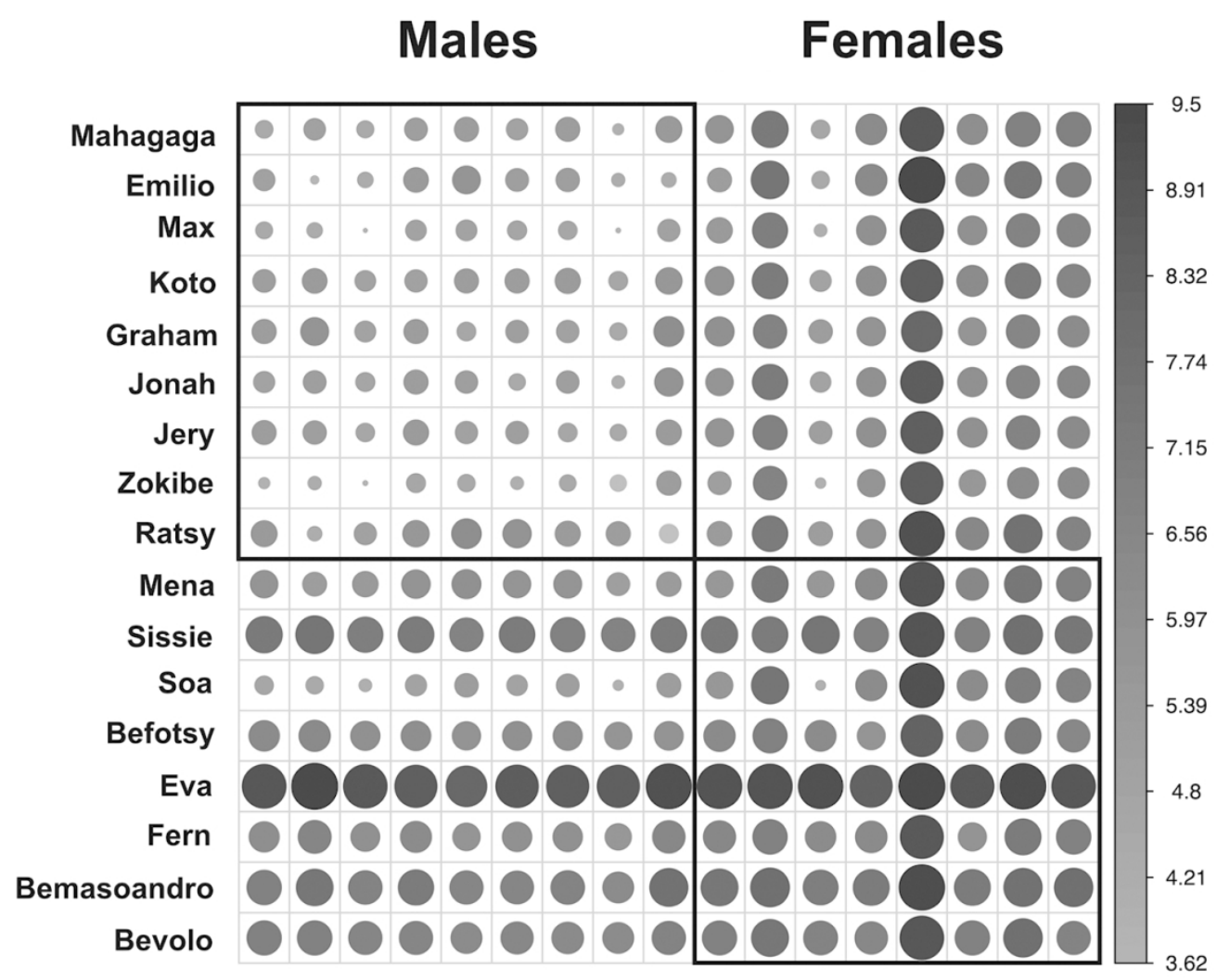

Figure 2: The Levenshtein Distances showing song structuring in male and female indris of the studied groups. Individuals are shown on the vertical axis; sexes are shown on the horizontal axis. Dot size and color refer to the Levenshtein Distance: the darker and bigger the dots, the higher are the distances between the individual contributions to the song. This plot was generated using the R package corrplot (vers. 0.84; Wei \& Simko, 2017). 


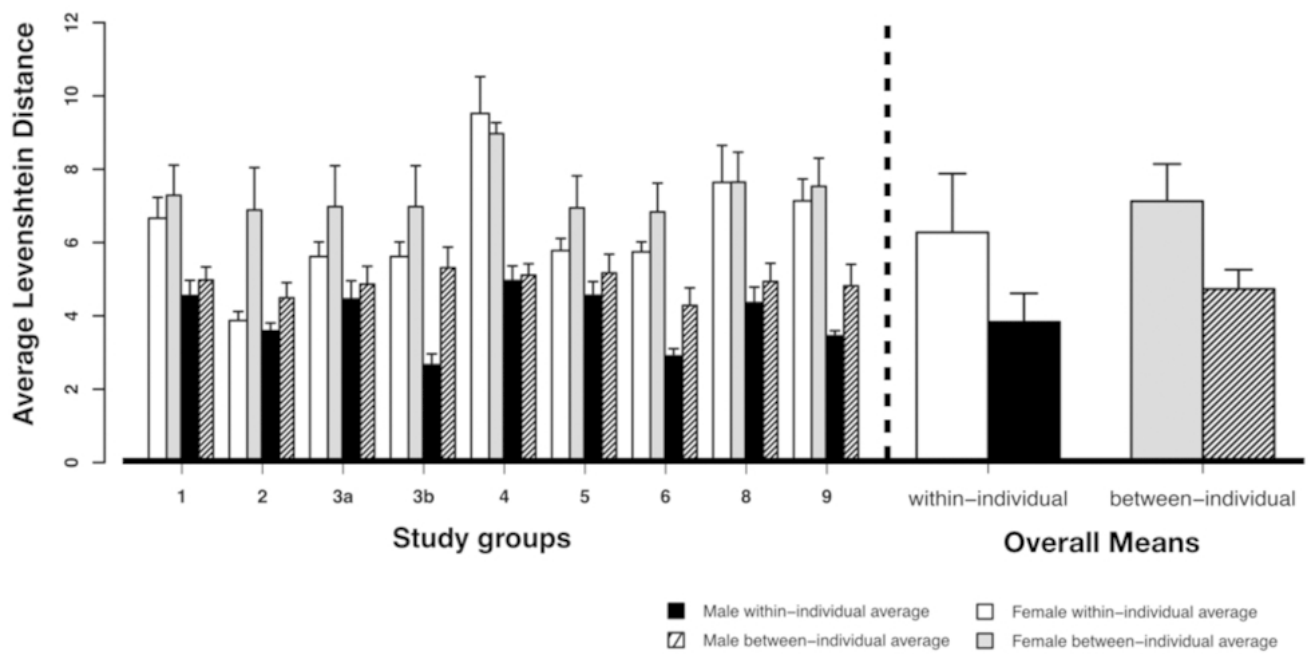

Figure 3: The average Levenshtein Distance among sexes and individuals, in the eight studied groups. Bar plot describing the individual and overall degree of stereotypy and variability expressed by the average Levenshtein Distances (LDs). Within-individual LDs are reported for females (white bars) and males (black bars), as well as between-individual LDs (grey bars for females, striped bars for males). Group 3 is reported twice because the male of the reproductive pairs changed in 2014. Capped lines represent Standard Deviation. 


\section{Sexually dimorphic phrase organization in the song of the indris (Indri indri)}

6 Anna Zanoli ${ }^{1}$, Chiara De Gregorio ${ }^{1}$, Daria Valente ${ }^{1}$, Valeria Torti ${ }^{1}$, Giovanna

7 Bonadonna ${ }^{1}$, Rose Marie Randrianarison ${ }^{2,3}$, Cristina Giacoma ${ }^{1} \&$ Marco Gamba $^{1}$

8

$9{ }^{1}$ Department of Life Sciences and Systems Biology, University of Torino, Torino, Italy

$10{ }^{2}$ Groupe d'Étude et de Recherche sur les Primates de Madagascar (GERP),

11 Antananarivo, Madagascar

$12{ }^{3}$ Mention d'Anthropobiologie et de Développement Durable (MADD), Université

13 d'Antananarivo, Antananarivo 101, Madagascar

16 Corresponding Author:

17 Marco Gamba ${ }^{1}$, Department of Life Sciences and Systems Biology, University of

18 Torino, Via Accademia Albertina 13, 10123 Torino, Italy, Tel. +39 0116704560

19 Email address: marco.gamba@unito.it 


\section{Abstract}

Animal acoustic communication often takes the form of complex sequences, composed of multiple distinct acoustic units, which can vary in their degree of stereotypy. Studies of sequence variation may contribute to our understanding of the structural flexibility of primates' songs, which can provide essential ecological and behavioral information about variability at the individual, population, and specific level and provide insights into the mechanisms and drivers responsible for the evolutionary change of communicative traits.

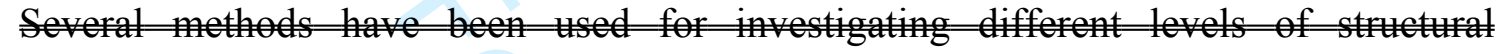
simila We studied intra and interindividual variation in the song structuring of a singing primate, the indri (Indri indri) Which inabits groups emit duets and choruses in which they combine long notes, short single units, and phrases consisting of a variable number of units (from two to six) with slightly descending frequency. Males' and females' contributions to the song differ in the temporal and frequency structure of song units and repertoire size. We calculated the similarity of phrase organization across different individual contributions using the Levenshtein distance, a logic distance that expressed the minimum cost to convert a sequence into another and can measure differences between two sequences of data. We then analyzed the degree of similarity within and between individuals and found that: i) the phrase structure of songs varied between reproductive males and females: female structuring of the song showed a higher number of phrases if compared to males; ii) Male contributions to the song were overall more similar to those of other males than were female contributions to the song of other females; iii) male contributions were more stereotyped than female contributions, which showed greater individual flexibility. The picture emerging from phrase combinatorics in 
60 the indris is in agreement with previous findings of rhythmic features and song repertoire

61 size of the indris, which also suggested that female songs are potentially less stereotyped

62 than those of males.

63 Keywords: syntax, language evolution, primates, singing, Levenshtein distance

64

65

66 Research Highlights

67 - This study demonstrated that male and female adult indris differed in the phrase

68

69

- Male contributions to the song were overall more similar to those of other males

70 and more stereotyped than females' ones.

71

72

Graphical Abstract

73

Figure 2 works as graphical abstract for this manuscript.

74

75

76

77

78

79 


\section{Introduction}

81 Communication between conspecifics often involves the use of vocalizations because

82 acoustic signals allow encoding a considerable amount of information in a short time

83 (Bradbury \& Vehrencamp, 2011). Animal vocal signals can be emitted in the form of

84 short vocalizations or given in sequences of variable length (Catchpole \& Slater, 2008).

85 In addition to the well-known example of birdsong, other animals such as insects,

86 amphibians, and mammals (including bats, rodents, primates, and cetaceans) also emit

87 complex acoustic sequences (Kershenbaum et al., 2016). Although animals showed a

88 limited ability to concatenate vocal emissions in phrases when compared to humans

89 (Berwick, Okanoya, Beckers \& Bolhuis, 2011), their vocal sequences may contain

90 information on species and individual identity (e.g., starlings (Sturnus vulgaris), wolves

91 (Canis lupus), dolphins (Tursiops truncatus), and rock hyraxes (Procavia capensis)).

92 Animal vocal sequences may also encode information about external cues such as

93 resource availability, e.g., food calls in chimpanzees (Pan troglodytes), or predator threats

94 in marmots (Marmota spp.; Kershenbaum et al., 2016).

95 The understanding of the role played by the acoustic sequences in a particular species'

96 repertoire often involves the comparison of sequences within and between individuals, as

97 well as within and between groups, so that it is possible to quantify the nature of the

98 variation and potentially correlate it to ecological and behavioral factors (Kershenbaum

99 et al., 2014).

100 So far, the studies of primate call organization focused on contact calls or alarm calls

101 (Clarke, Reichard \& Zuberbühler, 2006) with scarce investigations of song structure

102 variation within contexts (Torti, Gamba, Rabemananjara \& Giacoma, 2013). There is a

103 lack of information about whether primate males and females combine units in songs 
using different phrase combinations. It is essential to examine the sex-dimorphic traits of primate songs because knowledge of sex differences in song organization may be critical in our understanding of what is biologically informative, especially in sexually monomorphic species. Moreover, information available on the variability within a species

108 is very little (Honda \& Okanoya, 1999; Takahasi, Yamada \& Okanoya, 2010). Few

109 investigations on primate vocal sequences are currently available and none of them are

110 evaluating the stereotypy of song structure between sexes using a string metric (Gustison,

111 Semple, Ferrer-i-Cancho \& Bergman, 2016). While traditional methods may not apply to

112 a wide array of questions, string metrics can be used to investigate different organizational

113 levels, are entirely objective, and their results are verifiable (Heeringa, 2004).

114 Indris (Indri indri, Gmelin, 1788) represent a distinctive species for studying vocal

115 communication because of their rich repertoire (Maretti, Sorrentino, Finomana, Gamba

116 \& Giacoma, 2010; Valente et al., 2019) and the impressive loud songs, unique among

117 lemurs (Gamba et al., 2016; Torti et al., 2017), which can be heard at a distance up to 2

$118 \mathrm{~km}$ (Pollock, 1986). Data on sound pressure levels revealed that the sound levels of the

119 indri's song reached $110 \mathrm{~dB}$ (estimated at $0.50 \mathrm{~m}$; Torti, pers. obs.). This level can be

120 compared to ring-tailed lemurs (Lemur catta), which showed a call amplitude ranging

121 between 85 and $89 \mathrm{~dB}$ (at $1 \mathrm{~m}$, Macedonia, 1993). The song of the indris, which lasts 40-

$122250 \mathrm{~s}$, consists of a long series of modulated units, organized in phrases (Gamba, Favaro,

123 Torti, Sorrentino \& Giacoma, 2011), uttered simultaneously by males and females,

124 including juveniles, of the same group (Maretti et al., 2010). These types of units are

125 emitted exclusively during the song (Valente et al., 2019).

126 Previous research showed that the indris can emit songs in different contexts and that the

127 song can elicit different behaviors depending on its acoustic structure. Songs given in 
different contexts showed differences in their temporal structure that are distinguishable by visual inspection of the spectrograms and by ear (Torti et al. 2013). Cohesion songs

130 were emitted when the individuals of a group were dispersed in their territory, while

131 advertisement songs were usually given when the animals of the same group were in visual contact at the boundary of their territory (Torti et al., 2013). Cohesion songs were followed by emitters traveling significantly further than following the advertisement

134 song, confirming the different functions of the song uttered in different contexts (i.e., 135 cohesion songs bring together the members of a group, and advertisement songs inform 136 neighbors about the sex, age, and status of singing individuals). Other studies have shown 137 that male and female contributions to the song differ, both quantitatively and 138 qualitatively, in the temporal structure of the units emitted (Giacoma, Sorrentino, 139 Rabarivola \& Gamba, 2010; Sorrentino, Gamba \& Giacoma, 2012). Vocal sexual 140 dimorphism is also present in the modulation of the frequency of vocal utterances, in the 141 duration of unit types and the rhythmic structure of a contribution (Gamba et al., 2016;

142 De Gregorio et al., 2018).

143 Since the indris' songs can be interpreted as a string of easily identifiable phrases (Gamba 144 et al., 2016), they represent an ideal case for the study of the variability of phrase 145 concatenation in primate songs. Among the methods for investigating different levels of 146 structural variation in acoustic displays, we chose the Levenshtein distance, which is a 147 quantitative method for measuring the similarity of sequences (hereafter LD; Margoliash, 148 Staicer \& Inoue, 1991). The LD is a logical distance commonly used to quantify the 149 difference between two strings of data (e.g., human words, sequences of visual 150 movements or sequences of song themes; Gooskens \& Heeringa, 2004). This technique 151 has often been used to measure similarity in human dialects (Wieling, Montemagni, 
152 Nerbonne \& Baayen, 2014), and it has been applied to animal vocal sequences, but for a

153 very limited number of species (Indigo bunting, Passerina cyanea, Margoliash et al.,

154 1991; Willow warbler, Phylloscopus trochilus, Gil \& Slater, 2000; Humpback whale,

155 Megaptera novaeangliae: Helweg, Cato, Jenkins, Garrigue \& McCauley, 1998; Tougaard

156 \& Eriksen, 2006; Garland et al., 2012).

157 Although songs are often referred to as a male's prerogative, we have particular insights

158 showing that monogamous females may also use the song overlapping male song

159 functions (e.g., Eastern whip bird (Psophodes olivaceus), Rogers, Langmore, \& Mulder,

160 2007; Levin, 1996a; 1996b). Females may use songs for mate attraction (Rogers et al.,

161 2007), and they may even show a more elaborated song repertoire (Australian magpies

162 (Gymnorhina tibice Brown \& Farabaugh, 1991). Like Eastern whip birds and Australian

163 magpies, indris are monogamous (Torti et al., 2017; Bonadonna et al., 2019), form groups

164 that occupy non-overlapping areas in the forest (Bonadonna et al., 2017), and use the

165 songs to inform neighboring groups about the occupation of a territory and to actively

166 defend resources during group encounters (Torti et al., 2013). Thus, we hypothesized that

167 the female contribution to the song would be structurally different from that of males.

168 Studies of song structure in bird duets also suggested that females' songs would be more

169 acoustically variable than that of males (Logue \& Gammon, 2004), in line with the

170 territorial model of bird duet evolution (Farabaugh, 1982). In birds, duetting occurs most

171 commonly where birds hold year-round territories, and it is associated with sexually

172 monomorphic species that form long-term monogamous pair bonds (Riebel, Odom,

173 Langmore \& Hall, 2019). Indri females showed significantly higher variation in the

174 rhythm of their contributions to the song and a higher potential to synchronize with males

175 (De Gregorio et al., 2018). Thus, we hypothesized that the adjustment in the rhythmic 
176 structure of their contribution would also be reflected in a sexually dimorphic phrases

177 combination, where one should expect males to produce songs with a more stereotyped

178 structure. Similarly to pair living bird species (Rogers et al., 2007), indri females may use

179 songs for mate guarding and attraction, and song structural variability and complexity

180 may have evolved to provide conspecifics with information on females' fitness and

181 survival.

182

183

184

185 Methods

186 Observations and recordings

187 We studied 8 groups $\left(\mathrm{N}=36\right.$ individuals) living in the Maromizaha Forest $\left(18^{\circ} 56^{\prime} 49^{\prime \prime} \mathrm{S}\right.$,

$\left.188 \quad 48^{\circ} 27^{\prime} 53^{\prime \prime} \mathrm{E}\right)$. We recorded the animals between 2011 and 2017. We observed one social

189 group per week, from Monday to Friday approximately from 6 AM to 1 PM, when the

190 animals usually start resting and sleeping until the day after (Pollock, 1975). All

191 recordings were carried out without the use of playback stimuli, and nothing was done to

192 modify the behavior of the indris. We recorded 142 songs, consisting of duets and

193 choruses with a maximum of five individuals singing in the same song. For the analysis,

194 we only considered the contribution of the reproductive individuals, for a total of 17 focal

195 animals from eight social groups: nine reproductive adult males, and eight reproductive

196 adult females. An example of an indri song and the singers' contributions is shown in

197 Figure 1. The different number of males and females is motivated by the fact that, during

198 the study period, the reproductive male of a group changed. All the songs were recorded

199 using solid-state recorders (Olympus LS05, Tascam DR-100, Tascam DR-05) with a 
200 sampling rate of $44.1 \mathrm{kHz}$ (16-bit depth) during all the recording sessions. When

201 recording the songs, we were always at a distance between 2 and $20 \mathrm{~m}$ from the animals,

202 with the microphone oriented toward the focal singing individuals. We always kept visual

203 contact with the vocalizing animals and maximized our efforts to face the focal animals

204 during the emission of the song. Since indri songs emitted in different contexts have

205 different acoustic structure, in order to avoid any bias due to these differences, we

206 considered, from multiple years, only those songs that were labeled as advertisement

207 songs and were recorded in the same context (Torti et al., 2013). Using the focal animal

208 sampling technique (Altmann, 1974), we were able to attribute each vocalization to its

209 signaler. We will refer to every individual uttered portion within a song or a chorus as an

210 'individual contribution'.

211 During this study, we did not have any physical contact with the animals, and we recorded

212 only spontaneously emitted songs. We have received permits for this research, each year,

213 from "Direction des Eaux et Forêts" and "Madagascar National Parks": 2011 - N

214 274/11/MEF/SG/D GF/DCB.SAP/SCB, 2012 N²45/12/MEF/SG/DGF/DCB.SAP/SCB,

2152014 - N066/14/MEF/SG/DGF/DCB.SAP/SCB, 2015 - N 180/ 15/ MEEMF/ SG/ DGF/

216 DAPT/ SCBT; 2016 - N 98/ 16/ MEEMF/ SG/ DGF/ DAPT/ SCB.Re and N² 217/

217 16/MEEMF/ SG/ DGF/ DSAP/ SCB.Re, 2017 - 73/17/MEEF/SG/DGF/DSAP/SCB.RE.

218 The data collection in 2013 did not require a permit because performed by our Malagasy

219 collaborators only.

220 We adhered to applicable international, national, and/or institutional guidelines for the

221 study on animals and nonhuman primates, including the American Society of

222 Primatologist (ASP) Principle for the Ethical Treatment of nonhuman Primates, and the 
223 European Union directive guidelines for the study on animals and nonhuman primates 224 (Directive 2010/63/EU). The study did not require IACUC approval.

\section{Acoustic and statistical analyses}

226 We edited segments containing indri songs using Praat 6.0.30 (Boersma \& Weenink 227 2008) and BORIS 5.1 (Friard \& Gamba 2016). For each recorded song, we created a 228 spectrogram with a view range between 0 and $5000 \mathrm{~Hz}$, a window length of $0.09 \mathrm{~s}$, and a 229 dynamic range of $65.0 \mathrm{~dB}$. We saved each song in a single audio file in WAV format 230 (Waveform audio file format). We saved the information related to the identity of each 231 singer in a Praat textgrid. We then labeled all the vocal units (each single sound 232 constituting the modulated part of the song; Thalmann, Geissmann, Simona \& Mutschler, 233 1993) according to their belonging to a song portion (long notes or descending phrases,

234 see Torti et al., 2013 for details) and to a descending phrase (hereafter, DP; see Torti et 235 al., 2017 for details). Songs given in different contexts showed differences in their 236 temporal structure that are distinguishable by visual inspection of the spectrograms and 237 by ear (Torti et al. 2013). We considered phrases consisting of two (DP2), three (DP3), 238 four (DP4), five (DP5), and six (DP6) units. This information was saved in Praat and 239 exported to a Microsoft $($ Excel spreadsheet (Gamba, Friard \& Giacoma, 2012). Since all 240 the steps of the labeling process have been done by a single operator (A.Z.), we avoided 241 the possibility of encountering errors due to observer differences. To understand whether

242 there were differences in song structure between sexes, we investigated the DPs similarity 243 in each contribution. We transformed each contribution in a string of labels separated by 244 a break symbol (e.g., DP2|DP3|DP4|DP3). The resulting string represents the 245 concatenation of the phrases uttered within a contribution (and it is a measure of phrase 
246 organization). From the 142 songs, we obtained 142 strings for females (with an average

247 of 17.88 songs per individual, $\mathrm{SD}=5.44$ ), and 119 strings for males (with an average of

24813.22 songs per individual, $\mathrm{SD}=5.91)$. Using $\mathrm{R}(\mathrm{R}$ Core Team, 2015; version 3.3.3), we

249 calculated the Levenshtein distance (LD) for each pair of strings

250 (package stringdist 0.9.4.2 in R; van der Loo, 2014) because this methodology provides

251 a robust quantitative approach for the study of animal acoustic sequences (Kershenbaum

$252 \&$ Garland, 2015). The distance calculates the minimum number of necessary changes

253 (insertions, deletions, and substitutions) to transform one string into another (Kohonen,

254 1985). We obtained a squared matrix consisting of the distances between each pair of

255 strings, then averaged LDs and calculated within- and between-individual means (Fig. 2),

256 to investigate whether females and males differed in their degree of variation. For this

257 purpose, we ran Mantel tests (9999 randomizations) using a matrix featuring the average

258 individual means against a model matrix consisting of 0 when the corresponding

259 individuals were of the same sex (Krull et al., 2012), and 1 when they were opposite sexes

260 (package vegan in R; Oksanen et al., 2013). When investigating differences at the group

261 level or within-sex, we used the non-parametric paired samples Wilcoxon test to compare

262 the average individual LDs of each member of a pair or the within- versus between-

263 individual LDs because, with such a small sample size, the Mantel test is not

264 recommended (Legendre \& Fortin, 1989). Only for the Wilcoxon test, the group in which

265 the male changed was entered twice, considering the two pairs as different groups. We

266 obtained a lower number of male contributions because the reproductive females also

267 engaged in duets with immature male offspring $(\mathrm{N}=23)$. 


\section{Results}

270 We analyzed 261 individual contributions consisting of a total of 2018 phrases. We 271 obtained $77 \pm 21$ (mean \pm standard deviation) phrases per male and $78 \pm 23$ phrases per

272 female. We found that average phrase duration was $1.285 \mathrm{~s}$ (range: $0.380-3.000 \mathrm{~s}$ ). The 273 number of phrases in the individual song ranged between 2 and 27.

274 We found a significant difference between the LDs calculated for males and females, 275 where females showed higher average individual means than males (Mantel test: $\mathrm{r}=$ 276 0.167, $\mathrm{P}=0.002$; Fig. 2). In all groups, the females had higher $\operatorname{LDs}(\mathrm{LD}=6.497+1.674)$ 277 than males $(\mathrm{LD}=3.946+0.814)$, showing that female contribution to the song was less 278 stereotyped (Fig. 3, Wilcoxon paired test: $\mathrm{V}=0, \mathrm{df}=7 ; \mathrm{P}=0.008$ ). It is noticeable that 279 the individuals Eva, which sang with three different males and had a high number of 280 recordings $(\mathrm{N}=39)$, showed remarkable differences compared to other females. Both 281 females and males showed a higher variability at between-individuals $\left(\mathrm{LD}_{\text {females }}=7.386\right.$ $\left.282+0.709, \mathrm{LD}_{\text {males }}=4.885+0.325\right)$ than within-individual level (Fig. 3), except for the 283 females of groups 4 and 8 . Overall, we found a significant difference between within- and 284 between-individual LDs (Wilcoxon paired test: $\mathrm{V}=0$, $\mathrm{df}=7 ; \mathrm{P}=0.008$ ).

\section{Discussion}

286 We examined differences in the order of phrases emitted during the songs by reproductive

287 male and female indris living in the same population. We hypothesized that female 288 contributions to the song may function differently in phrase concatenation from those of 289 males. We found support for our predictions. The phrase structure of songs indeed 290 differed between males and females, and female contributions were less stereotyped than 
291 those of males. The LDs showed that the between-individual stereotypy of male 292 contributions was higher than females' one. Males, therefore, appeared to produce songs 293 that are overall more similar to those of other males. In agreement with previous studies 294 that reported sexual dimorphism in the overall timing and repertoire size (Giacoma et al., 295 2010), and in the frequency modulation, duration and rhythm (Gamba et al., 2016; Torti 296 et al., 2017, De Gregorio et al., 2018), we found that male and female indris also differed 297 in the phrase organization of their songs. Female structuring of the song showed a higher 298 number of phrases if compared to males, independently of the phrases being of the same 299 or different type. This result is in line with previous studies on family-living and pair300 bonded primate and bird species (Deputte, 1982; Savage, Snowdon, Giraldo \& Soto, 301 1996; Snowdon, 2017; Riebel et al., 2019; Levin, 1996a; 1996b), endorsing that in a 302 socially monogamous, monomorphic species which holds year-round territories, sex 303 differences in vocal output are frequent (Marshall \& Marshall, 1976). Furthermore, 304 despite the fact that songs are considered to be males' peculiar features (Cowlishaw, 305 1996), our results confirm that also monogamous females use songs and that female song 306 can be more elaborate than those of males. Female song phrase concatenation is more 307 complex than males' because even if males are playing the primary role in territorial 308 defense, females' role in territorial disputes can be essential. Female songs may be critical 309 for advertising their identity as well as resources holding potential. For instance, vocal 310 fights, in which females and males are singing together, are often sufficient to resolve 311 group encounters, reducing the occurrence of physical fights (Bonadonna et al., 2020).

312 Future studies may investigate whether female dispersal distance and territorial changes 313 over the years may contribute to a deeper understanding of this sex-dimorphic variation.

314 Expanding previous findings that showed how indri female contribution to the song was 
315 more varied in the rhythm (De Gregorio et al., 2018), we showed that the combination 316 and repertoire of the phrases are also more extensive than those shown by males. Females 317 not only have a broader repertoire of units, but they also emit descending phrases that we 318 did not observe in males (e.g., descending phrases of six units). Considering those 319 previous findings, our results may suggest that the differences in song structuring could 320 be used to convey information about the sex and the status of the singers that can be 321 assessed at a distance by conspecifics.

322 In agreement with previous findings on the different role of males and females during the song (Giacoma et al., 2010), we found that female song is potentially more distinctive than the male one. These results are in agreement with previous findings on birds (Brown \& Farabaugh, 1991), confirming that in those species in which females are involved in territorial defense, their repertoires are as large or larger than those of males, on the level

327 of both units and phrases. Territorial defense is crucial for survival and reproduction in 328 pair-bonding species that occupy stable territories, and even if female involvement in territorial defense is different from that of the reproductive male, they participate in

330 joining with their partner. An increasing body of literature (e.g., Hall, Rittenbach, \& 331 Vehrencamp, 2015) supported the view that same-sex competition is the primary driver 332 of female song elaboration. It can be the case of the indris, where females may benefit 333 from multiple mating partners to increase tolerance by neighboring males (Bonadonna et 334 al., 2014). As mentioned above, females can advertise the occupancy of an area as well 335 as their quality and resource-holding potential. In support of the higher variability in 336 female song structure, there is also the recent evidence that genetic relatedness may play 337 a critical role in determining the characteristics of DPs in males, whereas it may have a 338 lesser impact on female songs (Torti et al., 2017). A more variable song structure may 
339 add up to a more flexible structuring of the phrase notes, but further investigations are 340 needed.

341 This work also expands on and complements previous studies on humpback whales

342 (Helweg et al., 1998; Tougaard \& Eriksen, 2006; Garland et al., 2012), showing that the

343 Levenshtein distance is simple, efficiently computable and highly applicable to any

344 behavioral data that are produced in a sequence. Our results confirmed that the

345 Levenshtein distance method is a simple but powerful technique that can be applied to

346 assess stereotypy or divergence between sexes.

\section{Acknowledgements}

349 We thank two anonymous Reviewers and the Editor for their careful reading of our

350 manuscript and their many insightful comments and suggestions. This research was

351 supported by Università degli Studi di Torino and by grants from the Parco Natura Viva-

352 Centro Tutela Specie Minacciate. We are grateful to GERP and Dr Jonah Ratsimbazafy.

353 We thank Dr, Cesare Avesani Zaborra and Dr Caterina Spiezio for helping us with the

354 organization of the field station in Maromizaha. We are grateful to the researchers and 355 the international guides, for their help and logistical support. We also thank San Diego 356 Zoo Global, LDVI, Dr Chia L. Tan. 


\section{References}

361 Altmann, J. (1974). Observational study of behavior: sampling methods. Behaviour, 49, 362 227-267. DOI: 10.1163/156853974X00534

363 Berwick, R. C., Okanoya, K., Beckers, G. J. L., \& Bolhuis, J. J. (2011). Songs to

364 syntax: the linguistics of birdsong. Trends in Cognitive Sciences, 15, 113-121. DOI:

$365 \quad 10.1016 /$ j.tics.2011.01.002

366 Boersma, P., \& Weenink, D. (2005). Praat: doing phonetics by computer [Computer 367 program].

368 Bonadonna, G., Torti, V., Sorrentino, V., Randrianarison, R. M., Zaccagno, M., Gamba, 369 M., \& Giacoma, C. (2017). Territory exclusivity and intergroup encounters in the indris 370 (Mammalia: Primates: Indridae: Indri indri) upon methodological tuning. The European 371 Zoological Journal, 84, 238-251. DOI: 10.1080/24750263.2017.1318184

372 Bonadonna, G., Torti, V., De Gregorio, C., Valente, D., Randrianarison, R. M., Pozzi, 373 L., M., Gamba, M., \& Giacoma, C. (2019). Evidence of genetic monogamy in the lemur 374 Indri (Indri indri). American Journal of Primatology, 81(6), e22993. DOI:

$375 \quad 10.1002 /$ ajp.22993

376 Bonadonna, G., Zaccagno, M., Torti, V., Valente, D., De Gregorio, C., Randrianarison, 377 R. M., ... \& Giacoma, C. (2020). Intra-and Intergroup Spatial Dynamics of a Pair-Living 378 Singing Primate, Indri indri: A Multiannual Study of Three Indri Groups in 379 Maromizaha Forest, Madagascar. International Journal of Primatology, 1-22. DOI: $380 \quad 10.1007 / \mathrm{s} 10764-019-00127-5$ 
381 Bradbury, J.W., \& Vehrencamp, S.L. (2011). Principles of animal communication.

382 Sinauer, Sunderland.

383 Brown, E. D., \& Farabaugh, S. M. (1991). Song sharing in a group-living songbird, the

384 Australian magpie, Gymnorhina tibicen. Part III. Sex specificity and individual

385 specificity of vocal parts in communal chorus and duet songs. Behaviour, 118, 244-274.

386 Catchpole, C. K., \& Slater, P. J. R. (2008). Bird song: biological themes and variations.

387 Cambridge University Press, Cambridge.

388 Clarke, E., Reichard, U. H., \& Zuberbühler, K. (2006). The syntax and meaning of wild

389 gibbon songs. PloS one, 1(1), e73. DOI: 10.1371/journal.pone.0000073

390 Cowlishaw, G. U. Y. (1996). Sexual selection and information content in gibbon song

391 bouts. Ethology, 102(2), 272-284. DOI: 10.1111/j.1439-0310.1996.tb01125.x

392 De Gregorio, C., Zanoli, A., Valente, D., Torti, V., Bonadonna, G., Randrianarison, R.

393 M., Giacoma, C., \& Gamba, M. (2019). Female indris determine the rhythmic structure

394 of the song and sustain a higher cost when the chorus size increases. Current Zoology,

395 65, 89-97. DOI: 10.1093/cz/zoy058

396 Deputte, B. L. (1982). Duetting in male and female songs of the white-cheeked gibbon

397 (Hylobates concolor leucogenys). In C. T. Snowdon, C. H. Brown, \& M. R. Petersen

398 (Eds.), Primate communication (pp. 67-93). New York: Cambridge University Press.

399 Farabaugh, S. M. (1982). The ecological and social significance of duetting. In: D. E.

400 Kroodsma \& E. H. Miller (Eds.), Acoustic Communication in Birds Vol. 2. (pp. 85-124).

401 New York, USA: Academic Press. 
402 Friard, O., \& Gamba, M. (2016). BORIS: a free, versatile open-source event-logging 403 software for video/audio coding and live observations. Methods in Ecology and 404 Evolution, 7, 1325-1330. DOI:10.1111/2041-210X.12584

405 Gamba, M., Favaro, L., Torti, V., Sorrentino, V., \& Giacoma, C. (2011). Vocal tract 406 Flexibility and variation in the vocal output in wild indris. Bioacoustics, 20, 251-265. 407 DOI: $10.1080 / 09524622.2011 .9753649$

408 Gamba, M., Friard, O., \& Giacoma, C. (2012). Vocal tract morphology determines 409 species-specific features in vocal signals of lemurs (Eulemur). International Journal of 410 Primatology, 33(6), 1453-1466. DOI:10.1007/s10764-012-9635-y

411 Gamba, M., Torti, V., Estienne, V., Randrianarison, R. M., Valente, D., Rovara, P., \&

412 Giacoma, C. (2016). The indris have got rhythm! Timing and pitch variation of a

413 primate song examined between sexes and age classes. Frontiers in neuroscience, 10, 414 249. DOI: $10.3389 /$ fnins.2016.00249

415 Garland, E. C., Lilley, M. S., Goldizen, A. W., Rekdahl, M. L., Garrigue, C., \& Noad, 416 M. J. (2012). Improved versions of the Levenshtein distance method for comparing 417 sequence information in animals' vocalisations: tests using humpback whale song. 418 Behaviour, 149, 1413-1441. DOI: 10.1163/1568539X-00003032

419 Giacoma, C., Sorrentino, V., Rabarivola, C., \& Gamba, M. (2010). Sex differences in 420 the song of Indri indri. International Journal of Primatology, 31, 539-551. DOI:

$421 \quad 10.1007 / \mathrm{s} 10764-010-9412-8$ 
422 Gil, D., \& Slater, P. J. (2000). Song organisation and singing patterns of the willow

423 warbler, Phylloscopus trochilus. Behaviour, 137(6), 759-782.

424 Gooskens, C. \& Heeringa, W. (2004). Perceptive evaluation of Levenshtein dialect

425 distance measurements using Norwegian dialect data. Language variation and change,

426 16, 189-207. DOI: 10.1017/S0954394504163023

427 Gmelin, J. F. (1788). Systema naturce: per Regna tria naturae, secundum classes,

428 ordines, genera, species, cum characteribus, differentiis, synonomis, locis (Vol. 1, No.

429 6). Beer.

430 Gustison, M. L., Semple, S., Ferrer-i-Cancho, R., \& Bergman, T. J. (2016). Gelada

431 vocal sequences follow Menzerath's linguistic law. Proceedings of the National

432 Academy of Sciences, 113, E2750-E2758. DOI: 10.1073/pnas.1522072113

433 Hall, M. L., Rittenbach, M. R., \& Vehrencamp, S. L. (2015). Female song and vocal

434 interactions with males in a neotropical wren. Frontiers in Ecology and Evolution, 3,

435 12. DOI: $10.3389 /$ fevo. 2015.00012

436 Heeringa, W. J. (2004). Measuring dialect pronunciation differences using Levenshtein

437 distance (Doctoral dissertation, University Library Groningen).

438 Helweg, D. A., Cato, D. H., Jenkins, P. F., Garrigue, C., \& McCauley, R. D. (1998).

439 Geographic variation in South Pacific humpback whale songs. Behaviour, 135, 1-27.

$440 \quad$ DOI: $10.1163 / 156853998793066438$

441 Honda, E. \& Okanoya, K. (1999). Acoustical and syntactical comparisons between

442 songs of the white-backed Munia (Lonchura striata) and its domesticated strain, the 
443 Bengalese finch (Lonchura striata var. domestica). Zoological Science, 16, 319-326.

444 DOI: $10.2108 /$ zsj.16.319

445 Kershenbaum, A., Blumstein, D. T., Roch, M. A., Akçay, Ç., Backus, G., Bee, M. A., ...

$446 \&$ Coen, M. (2016). Acoustic sequences in non-human animals: a tutorial review and

447 prospectus. Biological Reviews, 91(1), 13-52. DOI: $10.1111 /$ brv.12160

448 Kershenbaum, A. \& Garland, E. C. (2015). Quantifying similarity in animal vocal

449 sequences: which metric performs best? Methods in Ecology and Evolution, 6, 1452-

450 1461. DOI: $10.1111 / 2041-210 X .12433$

451 Kershenbaum, A., Bowles, A. E., Freeberg, T. M., Jin, D. Z., Lameira, A. R., \& Bohn,

452 K. (2014). Animal vocal sequences: not the Markov chains we thought they

453 were. Proceedings of the Royal Society B: Biological Sciences, 281(1792), 20141370.

454 DOI: $10.1098 \% 2 F r s p b .2014 .1370$

455 Kohonen, T. (1985). Median strings. Pattern Recognition Letters, 3, 309-313. DOI:

$456 \quad 10.1016 / 0167-8655(85) 90061-3$

457 Krull, C. R., Ranjard, L., Landers, T. J., Ismar, S. M., Matthews, J. L., \& Hauber, M. E.

458 (2012). Analyses of sex and individual differences in vocalizations of Australasian

459 gannets using a dynamic time warping algorithm. The Journal of the Acoustical Society

460 of America, 32, 1189- 98. DOI: 10.1121/1.4734237

461 Legendre, P., \& Fortin, M. J. (1989). Spatial pattern and ecological

462 analysis. Vegetatio, 80(2), 107-138. 
463 Levin, R. N. (1996a). Song behaviour and reproductive strategies in a duetting wren,

464 Thryothorus nigricapillus: I. Removal experiments. Animal Behaviour, 52, 1093-1106.

465 DOI: 10.1006/anbe.1996.0257

466 Levin, R. N. (1996b). Song behaviour and reproductive strategies in a duetting wren,

467 Thryothorus nigricapillus: II Playback experiments. Animal Behaviour, 52, 1107-1117.

468 DOI: 10.1006/anbe.1996.0258

469 Logue, D. M., \& Gammon, D. E. (2004). Duet song and sex roles during territory

470 defence in a tropical bird, the black-bellied wren, Thryothorus fasciatoventris. Animal

471 Behaviour, 68(4), 721-731. DOI: 10.1016/j.anbehav.2003.10.026

472 Macedonia, J. M. (1993). The vocal repertoire of the ring-tailed lemur (Lemur

473 catta). Folia primatologica, 61(4), 186-217.

474 Maretti, G., Sorrentino, V., Finomana, A., Gamba, M., \& Giacoma, C. (2010). Not just

475 a pretty song: an overview of the vocal repertoire of Indri indri. Journal of

476 Anthropological Sciences, 88, 151-165.

477 Margoliash, D., Staicer, C. A., \& Inoue, S. A. (1991). Stereotyped and plastic song in

478 adult indigo buntings, Passerina cyanea. Animal Behaviour, 42, 367-388. DOI:

$479 \quad 10.1016 / \mathrm{S} 0003-3472(05) 80036-3$

480 Marshall, J. T., \& Marshall, E. R. (1976). Gibbons and their territorial songs. Science, $481 \quad 193,235-237$. 
482 Oksanen, J., Blanchet, F. G., Kindt, R., Legendre, P., Minchin, P. R., O’hara, R. B., ... 483 \& Oksanen, M. J. (2013). Package 'vegan'. Community ecology package, version, 2(9), $484 \quad 1-295$.

485 Pollock, J. I. (1975). The social behaviour and ecology of Indri indri (Doctoral 486 dissertation, University of London).

487 Pollock, J. I. (1986). The song of the Indris (Indri indri; Primates: Lemuroidea): natural 488 history, form and function. International Journal of Primatology, 7, 225-267. DOI:

$489 \quad 10.1007 / \mathrm{BF} 02736391$

490 R Core Team (2015). R: A Language and Environment for Statistical Computing.

491 Vienna: R Foundation for Statistical Computing. Available online at: http://www.R-

492 project.org/

493 Riebel, K., Odom, K. J., Langmore, N. E., \& Hall, M. L. (2019). New insights from

494 female bird song: towards an integrated approach to studying male and female

495 communication roles. Biology letters, 15(4), 20190059. DOI: 10.1098/rsbl.2019.0059

496 Rogers, A. C., Langmore, N. E., \& Mulder, R. A. (2007). Function of pair duets in the 497 eastern whipbird: cooperative defense or sexual conflict?. Behavioral Ecology, 18(1), 498 182-188. DOI:10.1093/beheco/arl070

499 Savage, A., Snowdon, C. T., Giraldo, H., \& Soto, H. (1996). Parental care patterns and 500 vigilance in wild cotton-top tamarins (Saguinus oedipus). In M. Norconk, A.

501 Rosenberger, \& P. A. Garber (Eds.), Adaptive radiations of neotropical primates (pp. 502 187-199). New York: Plenum Press. 
503 Snowdon, C. T. (2017). Vocal communication in family-living and pair-bonded

504 primates. In Primate Hearing and Communication (pp. 141-174). Springer, Cham.

505 Sorrentino, V., Gamba, M., \& Giacoma, C. (2012). A quantitative description of the

506 vocal types emitted in the indri's song. Leaping ahead: advances in prosimian biology,

507 315-322. DOI: 10.1007/978-1-4614-4511-1_35

508 Takahasi, M., Yamada, H., \& Okanoya, K. (2010). Statistical and Prosodic Cues for

509 Song Segmentation Learning by Bengalese Finches (Lonchura striata var. domestica).

510 Ethology, 116, 481-489. DOI: 10.1111/j.1439-0310.2010.01772.x

511 Thalmann, U., Geissmann, T., Simona, A., \& Mutschler, T. (1993). The indris of

512 Anjanaharibe-Sud, northeastern Madagascar. International Journal of

513 Primatology, 14(3), 357-381.

514 Torti, V., Gamba, M., Rabemananjara, Z. H., \& Giacoma, C. (2013). The songs of the

515 indris (Mammalia: Primates: Indridae): contextual variation in the long-distance calls of

516 a lemur. Italian Journal of Zoology, 80, 596-607. DOI: 10.1080/11250003.2013.845261

517 Torti, V., Bonadonna, G., De Gregorio, C., Valente, D., Randrianarison, R. M., Friard,

518 O., ... Giacoma, C. (2017). An intra-population analysis of the indris' song dissimilarity

519 in the light of genetic distance. Scientific reports, 7, 10140. DOI: 10.1038/s41598-017-

$520 \quad 10656-9$

521 Tougaard, J., \& Eriksen, N. (2006) Analysing differences among animal songs

522 quantitatively by means of the Levenshtein distance measure. Behaviour, 143, 239-252.

523 DOI: $10.1163 / 156853906775900685$ 
524 Valente, D., De Gregorio, C., Torti, V., Miaretsoa, L., Friard, O., ...Gamba M. (2019).

525 Finding Meanings in low dimensional structures: Stochastic Neighbor Embedding

526 applied to the analysis of Indri indri vocal repertoire. Animals, 9, 5, 243. DOI:

$527 \quad 10.3390 /$ ani 9050243

528 van der Loo, M. (2014). The stringdist package for approximate string matching. The $R$

529 Journal, 6, 111-122. https://CRAN.R-project.org/package=stringdist

530 Wei, T., \& Simko, V. (2017). R package "corrplot": Visualization of a Correlation

531 Matrix. https://github.com/taiyun/corrplot

532 Wieling, M., Montemagni, S., Nerbonne, J., \& Baayen, R. H. (2014). Lexical

533 differences between Tuscan dialects and standard Italian: Accounting for geographic

534 and sociodemographic variation using generalized additive mixed modeling. Language,

535 90, 669-692. DOI: 10.1353/lan.2014.0064

536 


\section{Figure legend:}

544 Figure 1: Spectrographic and schematic representation of an indri song. Spectrograms

545 of an indri song (a) showing a typical sequence of units given by one male and one

546 female. Schematic representation of the fundamental frequency of the descending

547 phrase units given by one male (b) and one female (c). Box fill patterns denote the

548 phrase type: black boxes mark single units (SU), horizontal lines boxes mark DP2,

549 diagonal lines boxes mark DP3, wavy lines boxes mark DP4, and checkered boxes mark

550 DP5. The spectrograms were generated in Praat with the following parameters: window

551 length: $0.05 \mathrm{~s}$; dynamic range: $50 \mathrm{~dB}$; frequency range: 0 to $10.000 \mathrm{~Hz}$ (a), 0 to 3.000

$552 \mathrm{~Hz}(\mathrm{~b}, \mathrm{c})$.

553 Figure 2: The Levenshtein Distances showing song structuring in male and female

554 indris of the studied groups. Individuals are shown on the vertical axis; sexes are shown

555 on the horizontal axis. Dot size and color refer to the Levenshtein Distance: the darker

556 and bigger the dots, the higher are the distances between the individual contributions to

557 the song. This plot was generated using the R package corrplot (vers. 0.84; Wei \&

558 Simko, 2017).

559 Figure 3: The average Levenshtein Distance among sexes and individuals, in the eight

560 studied groups. Bar plot describing the individual and overall degree of stereotypy and

561 variability expressed by the average Levenshtein Distances (LDs). Within-individual

562 LDs are reported for females (white bars) and males (black bars), as well as between-

563 individual LDs (grey bars for females, striped bars for males). Group 3 is reported twice

564 because the male of the reproductive pairs changed in 2014. Capped lines represent

565 Standard Deviation. 